\title{
Temporalidad y Espacialidad en la modernidad tardía: El advenimiento de la fluidez
}

\section{Daniel Carrasco Bahamonde}

Sociólogo, Universidad ARCIS Chile

danielcarrasco_41@yahoo.com

Resumen

\begin{abstract}
El tiempo y el espacio constituyen categorías básicas de la experiencia humana, aun cuando su real alcance no haya reclamado para sí una preocupación teóricometodológica suficientemente acabada. La tan mentada transición a la posmodernidad no puede ser comprendida sino a condición de revisar las transformaciones que la consciencia del tiempo y el espacio ha experimentado durante el transcurso de las últimas décadas. Sólo así, mediante un análisis que se aboque a la elucidación de la especificidad histórica de esta nueva condición, ha de ser posible comprender de manera rigurosa la real naturaleza de las transformaciones que han comenzado a evidenciarse en los procesos culturales e identitarios, como también la reconfiguración del lazo social en condiciones de posmodernidad. Con vistas a dicho fin, el presente estudio se aboca sucintamente a reconocer dichas mutaciones, sus implicancias y consecuencias en la vida sociocultural.
\end{abstract}

\section{Abstract}

\begin{abstract}
Time and space are basic categories of human experience, even if its real scope has not claimed for itself a sufficient theoretical and methodological concern over. The much talked about transition to post-modernity cannot be understood only on condition of reviewing the changes that the consciousness of time and space has experienced over the course of recent decades. Only then, through an analysis that will lead to the elucidation of the historical specificity of this new condition, it should be possible to rigorously understand the real nature of the changes that have begun to surface in cultural and identity processes, as well as the reconfiguration of social ties in terms of postmodernism. With a view to that end, this study briefly orients to recognize these mutations, their implications and impact on socio-cultural life.
\end{abstract}

\section{Palabras Clave: Tiempo, espacio, posmodernidad, comunidad, sociedad}

Keywords: Time, space, postmodernity, community, society

\section{Introducción}

El tiempo y el espacio constituyen categorías básicas de la experiencia humana, estableciéndose como los vehículos fundamentales para la codificación y reproducción de las relaciones sociales; su ordenamiento simbólico y material conforma un marco de sentido para la experiencia individual y colectiva que no sólo estructura la representación que se hace del mundo, sino también el lugar que en éste se ocupa. (Jameson, 1995; Bauman, 2007; Harvey, 2002; Giddens, 1997). Sin embargo, su importancia no parece corresponderse con una adecuada comprensión de su real 
alcance; su gravedad pareciera ser habitualmente descuidada, constituyendo un campo de problemas naturalizado y reificado, cuya discusión tiende ha ser soterrada. Más bien, son tratados ingenuamente como aspectos normativos de la vida social que asumen significación mediante criterios objetivos de valoración: el tiempo al igual que el espacio tienden a ser inscritos en escalas de valores objetivos, observables, mensurables y auto-evidentes.

Aun cuando es posible identificar modalidades del tiempo y el espacio relativas, derivadas básicamente de la experiencia subjetiva de los individuos o grupos, éstas son tradicionalmente concebidas como malformaciones de su proyección originaria, reclamando la restitución de un sentido primigenio descontaminado de residuos relativistas. La objetividad de las representaciones espacio-temporales, como también de sus propiedades de funcionalidad y factibilidad, han de reclamar, en última instancia, una especificidad que trasciende las modalidades particulares del individuo o el grupo.

Ahora bien, esta modalidad deshistorizante se encuentra preñada de una contradicción insalvable; a saber, el desconocimiento esencial de las prácticas y procesos materiales de la reproducción social que se encuentran a su base. Su determinación es situada por fuera de las condiciones materiales y simbólicas en las que necesariamente se inscribe, introduciendo ambigüedades y contradicciones en su estudio. Así, la concepción que tiende a reducir el tiempo y el espacio a un sentido único y objetivo no hace sino desconocer los procesos de producción social y material mediante los cuales su objetividad, que desde luego nunca es completa, adquiere valor.

Estudios recientes han puesto de manifiesto las debilidades interpretativas contenidas en esta perspectiva, insistiendo en que un análisis riguroso de las formas del tiempo y las estructuras del espacio debe reconocer el hecho de que no es posible asignar significados objetivos con independencia de los procesos y prácticas materiales que sirven como base para la reproducción de la vida social (Harvey, 2002; Giddens, 1997)). De igual modo que la época industrial, cada formación social particular ha de reclamar para sí una experiencia específica del tiempo y el espacio, susceptible de ser objetivada en dispositivos coherentes con su desligue histórico. Esto no significa, como puede apreciarse, el desconocimiento de su dimensión objetiva, sino más bien, el reconocimiento de los procesos de producción sociales y materiales que participan en la construcción de dicha objetividad. No se trata -señalará D. Harvey (2002) al momento de abordar los orígenes del cambio cultural- de sostener una total disolución del distingo entre lo objetivo y lo subjetivo, sino más bien de la "necesidad de reconocer las múltiples cualidades objetivas que el tiempo y el espacio pueden expresar, y el rol de las prácticas humanas en su construcción (...) La objetividad del tiempo y el espacio está dada, en cada caso, por las prácticas materiales de la reproducción social $y$, si tenemos en cuenta que éstas última varían geográfica e históricamente, sabremos que el tiempo social y el espacio social están construidos de manera diferencial" (p. 228).

Es precisamente en este plexo interpretativo -abocada a poner en suspenso la idea de un sentido único y objetivo del tiempo y el espacio a partir del cual podrían definirse las distintas concepciones y percepciones humanas- que se han de inscribir las inquietantes tesis sobre el tránsito de la modernidad a la posmodernidad; entendiendo por esta última no sólo la organización interna de una retórica estilística determinada, sino más bien el régimen de una dominante cultural que reclama para sí la presencia de lógicas residuales, emergentes y heterogéneas históricamente subordinadas. El hecho de que la naturaleza y profundidad de este tránsito sean aún materia de debate 
(no sólo como instrumento de argumentación, sino también como objeto de discusión), ha llevado a una serie de pensadores contemporáneos a proponer conceptualizaciones abocadas a dilucidar aquella mutación que hasta el momento sólo se presentaba como una suerte de indicador epistemológico ${ }^{1}$. Posmodernidad (Lyotard, 1979), Segunda Modernidad (Beck, 2002), Modernidad líquida (Bauman, 2007), Modernidad radical o tardía (Giddens, 1997), han sido sólo algunos de los términos que han intentado, cada uno a su manera, dar cuenta de la especificidad de esta nueva experiencia histórica ${ }^{2}$. Acontece así, un desplazamiento en la sensibilidad, en las prácticas y formaciones discursivas, que, distinguiéndose del horizonte propiamente moderno, transciende la experiencia estrictamente estética (posmodernismo), de la cual ciertamente se origina, para diseminarse en los distintos ámbitos de la vida social. Se acusa, en este sentido, una transformación de la propia esfera de la cultura en la sociedad contemporánea. Filosofía, antropología, sociología, arte, urbanismo, literatura, lingüística, ciencia política, teología, entre otros, han de ser los diversos campos sobre los cuales la comprensión espacio-temporal de la posmodernidad diseminará su influencia; donde la aceptación de lo efímero, la fragmentación, la discontinuidad y lo contingente, pareciera ser su condicionante más extraordinario.

Aun cuando las transformaciones espacio-temporales que esta última acusa constituyan por el momento tendencias, lo que muchas veces dificulta su comprensión categorial, no hay duda de que estas han acontecido (Jameson, 2007; Giddens, 1999). En lo que sigue, se intentará caracterizar brevemente las transformaciones que las coordenadas del tiempo y el espacio han experimentado en lo que se ha dado en llamar tránsito hacia la posmodernidad. Entendidos como los vehículos fundamentales de la codificación y reproducción de la vida social, se enfatizará en las transformaciones que una nueva comprensión espacio-temporal representa para las prácticas y procesos socio-culturales en las sociedades contemporáneas.

\section{Temporalidad y Especialidad en la Modernidad Tardía}

Al momento de intentar profundizar en el denso núcleo organizativo a partir del cual la consciencia moderna de época tiene lugar, podemos identificar una constante y decisiva preocupación por justificar y fundamentar la normatividad de la experiencia moderna desde la lógica interna de sus características propias, mediante la afirmación acontecimetal de su excepcionalidad; negándose a la idea de auto-concebirse como la simple prolongación de una tradición a sus ojos decadente (Habermas,1989; Bauman, 2007). Teniendo como objetivo liberar a los hombres del miedo y constituirlos en señores, por medio de un proceso evolutivo de desacralización o desencantamiento de las imágenes mítico-religiosas del mundo, que encubren y mitifican el sufrimiento de los hombres y la injusticia que lo origina, la modernidad pretende inaugurar una nueva época, profundamente determinada por un progresivo proceso iluminador de apropiación y reapropiación de lo que juzgaba era la verdadera naturaleza de una realidad esencial, compleja pero unificada; proceso intensamente marcado por la creencia en un permanente y decisivo camino de superación crítica, donde el pensamiento occidental se presenta como base y acceso únicos al fundamento de las cosas. La premisa central de dicha época inaugural de la humanidad consistiría en la idea de que la razón, en su libre y público despliegue, ha de salvaguardar a los hombres del miedo y la barbarie propios de las experiencias mítico-religiosas que marcaron profundamente, desde el mito primitivo hasta la compleja metafísica del cristianismo, la experiencia del mundo premoderno. Esta apertura compensatoria de la razón, en su más autentico despliegue, ha de levantar los cimientos a partir de los cuales el hombre, ahora libre y autónomo, habría de sacudirse de todos los residuos metafísico-religiosos que tiempo atrás lo envestían. Auto-comprensión de la 
modernidad que encontrará su condición de posibilidad en una re-configuración radical de la consciencia del tiempo y el espacio.

Asumiendo en su radicalidad el hecho de que la experiencia del espacio y el tiempo constituyen los vehículos fundamentales para la codificación y reproducción de la vida social, donde un cambio en las formas de representación de las primeras genera algún tipo de transformación en las segundas, la modernidad ha de asumir como tarea fundamental la reconfiguración de dicha experiencia. Si se tiene en cuenta que el tiempo y el espacio constituyen, en primera instancia, propiedades intrínsecas de la naturaleza, independientes de la participación humana, la conquista y ordenamiento racional de las formas temporales y las estructuras espaciales se convertirá en un anhelo central del proyecto de modernización. Acontecerá un proceso gradual de reconfiguración que generará una revolución de tal magnitud en la cualidades objetivas del tiempo y el espacio que obligará a modificar, a veces de manera radical, las representaciones posibles del mundo (Harvey, 2002). Así, en nuevo orden posttradicional que la modernidad pretende expresar ha de instalar los cimientos conceptuales para una nueva comprensión espacio-temporal, en la cual la ambigüedad de la naturaleza se reconoce a sí misma en la barbarie, lo salvaje y lo pasado, y donde el presente se inscribe al interior de un proceso continuo y progresivo de reflexión crítica y emancipación expansiva.

La experiencia del tiempo, largamente determinada por el devenir de lo vivencial, ha de ser inscrita en la cuadratura racionalizante de su estandarización y universalización. La unidad y la calculabilidad, tal como lo señalaran críticamente Adorno y Horkheimer (1998), han de constituir las coordenadas básicas sobre las cuales el tiempo comenzará a ser entendido, ya no como un permanente flujo informe, sino más bien como una división mecánica fijada por las oscilaciones del péndulo, susceptible de ser gobernado por la predicción científica, la planificación racional y la institucionalización de sistemas abstractos de regulación y control (Harvey, 2002). La temporalidad será graficada en la forma de un progreso lineal en el cual la razón y la libertad serán las directrices; donde la preocupación por el futuro constituirá el complejo entramado en el cual la concepción homogénea y universal del tiempo comenzara a fraguarse.

La invención del reloj, que determinó el desarrollo de la revolución industrial, ha de constituir un hito central en este proceso de universalización y estandarización de las coordenadas temporales: "La concepción del pasado y del futuro conectados linealmente por el tictac del reloj dio lugar al florecimiento de toda clase de concepciones científicas e históricas. En este tipo de esquema temporal era posible ver la reintroducción y la predicción como proposiciones simétricas y formula un fuerte sentido de potencialidad para controlar el futuro. $Y$ si bien hicieron falta muchos años para que se aceptaran las escalas temporales geológica y evolutiva, en cierto sentido ya estaban implícitas en la aceptación misma del cronómetro como forma de medir el tiempo" (Harvey, 2002; p. 279).

Asimismo la colonización del espacio se convirtió en una coordenada básica para la planificación racional del futuro. Su estandarización produjo una concepción del espacio geométrica y sistemáticamente organizada que proporcionará un sentido de armonía y estabilidad frente al devenir incalculable y caótico de la naturaleza; anulando toda huella de la experiencia comprometida en su producción, su comprensión se convirtió en un sistema abstracto y normalizado, estrictamente funcional para el ordenamiento de los fenómenos espaciales. Así, desprovistos de todos los elementos de la fantasía y de las creencias que gobernaron su traducción premoderna, los trazados racionales del espacio consiguieron, con una concepción abstracta, homogénea y universal, un marco 
de pensamiento y acción que resultaba estable y discernible: surge, por primera vez en la historia, la posibilidad de concebir el globo de la tierra como una totalidad espacial cognoscible objetivamente, donde "los principios matemáticos podían aplicarse (...) a todo el problema de la representación del globo sobre una superficie plana (...) era como si el espacio, aunque infinito, pudiera ser conquistado y contenido por la acción y la ocupación humana" (Harvey, 2002; pp. 273-274). La objetividad, funcionalidad y factibilidad de las representaciones espaciales, así logradas, no sólo posibilitará la exactitud en la navegación, el establecimiento de las fronteras nacionales, la delimitación de las rutas de comunicación y comercio, sino también la emergencia de los Estados nacionales y la propiedad privada de la tierra; fenómenos centrales que condicionarán el desarrollo geopolítico y económico del proyecto moderno en su totalidad.

Ahora bien, la hegemonía de la comprensión espacio-temporal dispuesta por la modernidad pareciera comenzar a resquebrajarse en el transcurso de las últimas décadas. Será posible identificar una lenta, pero innegable y progresiva, transformación en el panorama cultural, político y económico internacional, cuya difícil conceptualización expondrá, en una suerte de impulso aglutinador, a los más importantes teóricos del orbe mundial ante una compleja situación (científicos, artistas, sociólogos y filósofos). Variados y múltiples habrán de ser los intentos por caracterizar y aprehender en su esencia la naturaleza siempre cambiante del nuevo horizonte experencial que comienza a configurarse, con claridad, en la década de 1970; mas una constante atravesará las diversas constelaciones discursivas que organizan la nueva escena internacional: la transformación en las prácticas culturales y económico-políticas ha acaecido en el seno mismo de la experiencia moderna del tiempo y el espacio, alterando su ordenamiento previo; ya sea como su consumación necesaria ya sea como su modalidad desbordada, la Modernidad ha dado paso a una nueva condición histórica, cuya elucidación depende, en última instancia, de la íntima relación que ésta establece con su prehistoria moderna.

F. Jameson (2007) es quizás quien ha apuntado de manera más penetrante en la dilucidación de la nueva condición histórica que esta transformación acusa: el advenimiento de dicha transformación global obedecería a una crisis en la experiencia del tiempo y el espacio, crisis en la que las categorías espaciales pasan a dominar a las temporales -que habían dominado claramente en la auto-comprensión elaborada por la modernidad-, mientras que ellas mismas sufren una mutación de la que resulta muy difícil dar cuenta en la actualidad. La discontinuidad de la experiencia temporal y la deslocalización de las coordenadas espaciales comenzarán a constituir los ejes del debate internacional, donde la modernidad en su fase tardía expresará una fractura respecto de su narrativa tradicional; experiencia radical que será conceptualizada en términos de Posmodernidad.

La posmodernidad comenzaría cuando el espacio y el tiempo, tradicionalmente entendidos, se separaran de la práctica vital, y entre sí, conformando campos autónomos, susceptibles de ser teorizados independientemente; dejando de ser aspectos entrelazados de la experiencia viva. Nótese que no se acusa un proceso unilateral, sino una dialéctica; lo que "no significa que desde ese momento ambos se conviertan en aspectos mutuamente extraños de la organización social (...) [sino más bien que] esta situación proporciona el fundamento mismo de su reconfiguración" permanente y móvil (Giddens, 1997; p. 29). Mientras que en el mundo premoderno, y hasta cierto punto también en el moderno, era posible reconocer una vinculación directa entre tiempo y espacio mediante la referencia a un lugar, la actualidad ha de caracterizarse por una profunda escisión global entre las conciencia espacio-temporal y 
la experiencia de su referencialidad; o, lo que es lo mismo, una creciente serie de combinaciones posibles que distorsionan la imbricación reguladora tradicionalmente atribuida. Tal como lo ha señalado Giddens (1997), el dinamismo de la modernidad reflexiva acontece en la forma de una separación entre espacio y tiempo que tiende progresivamente a estimular procesos globales de reestructuración del tejido social, donde no sólo el tiempo se ve vaciado, sino que también, como consecuencia de lo anterior, el espacio tiende a desvincularse de su determinación local, configurando un mundo social y experiencialmente distinto del de todas las épocas anteriores.

Esta dialéctica entre vaciamiento del tiempo y deslocalización del espacio, que caracteriza el dinamismo de la modernidad radical, ha de apoyarse, básicamente, en mecanismo precisos de desenclave propensos a extraer las relaciones sociales de sus circunstancias locales para luego reorganizarlas en regiones espacio-temporales indefinidas ${ }^{3}$; la fragmentación y la discontinuidad habrán de evidenciase en su desnudez. No hay duda de que la modernidad habría asumido, y hasta cierto punto asimilado, la experiencia acelerada y fragmentaria de la dinámica social; sin embargo ésta, a diferencia de la modernidad tardía o posmodernidad, sólo es capaz de concebirla como condición de posibilidad para la identificación de su esencia reguladora, conduciéndola, en un segundo momento, al campo racionalizado de las unidades ideales y la administración total (Adorno \& Horkheimer, 1998). En contraposición, la posmodernidad, en lugar de contrarrestar o trascender la experiencia de la fragmentación y la transitoriedad, hace de ésta el punto de partida de todo posible horizonte de sentido espacio-temporal: proliferación, yuxtaposición, disyunción, multiplicidad, movilidad, fluidez, han de constituir el plexo semántica del cambio cultural.

El tiempo es en la actualidad una función de la velocidad, y evidentemente sólo perceptible en términos de su celeridad y vaciamiento. La inmediatez de los acontecimientos, incrementada por el desarrollo de las tecnologías de la comunicación y la sociedad globalizada, han implicado que la experiencia del presente se vuelva poderosa y abrumadoramente vívida y material (Harvey, 2002). F. Jameson (2007) ha insistido en el hecho de que asistimos a un período en el que la conciencia del pasado sólo se corresponde con un montón de imágenes y de simulacros, y en el que el futuro es cada vez más difícil de imaginar. El ideal moderno de colonizar el futuro, inscrito en el continuo despliegue de la razón en la historia, ha de dar paso a una concepción del tiempo determinada por una pérdida de continuidad histórica que es percibida de manera intensa en las distintas sociedades: el presente se hace más importante que el pasado y el futuro, y conforme nuestro sentido del tiempo histórico ha cambiado profundamente, también lo ha hecho nuestro sentido existencial. Ciertamente esta mutación en la comprensión temporal de la vida posmoderna es reflejada en los dispositivos culturales dispuestos por la sociedad de consumo y espectáculo: "la imagen, la apariencia, el espectáculo pueden experimentarse con una intensidad (júbilo o terror) que sólo es posible porque se los concibe como presentes puros y desvinculados en el tiempo (...) la inmediatez de los acontecimientos, el sensacionalismo del espectáculo (político, científico, militar, así como los del entretenimiento) se convierten en la materia con la que está forjada la consciencia" (Harvey, 2002; p. 72). En consecuencia, la pérdida de la profundidad que trae consigo la primacía de la inmediatez y el deterioro de la memoria histórica ha de imprimir en la emergente comprensión temporal el sello de la fragmentación, la fugacidad, la transitoriedad; cuyas implicancias habrán de afectar los sentimientos mismos de continuidad y orden de las cosas, incluidos aquellos que no caen directamente dentro del entorno perceptivo del individuo. 
Respecto a la comprensión espacial implícita en la época posmoderna, es posible reconocer una creciente interconexión entre los dos extremos de la datación espacial universal: la extensionalidad y la intencionalidad, las tendencias universalizadoras y las disposiciones personales. El espacio socialmente significado ha de operar una mutación estructural en su comprensión, donde el proceso de globalización, entendido como el revés tecnológico-productivo complementario de la posmodernidad cultural, ha de jugar un rol fundamental. Las transnacionalización del capital financiero, la creciente fuerza de los flujos migratorios, la especialización de los medios de comunicación, son sólo algunos de los fenómenos que han contribuido a un creciente proceso de deslocalización y re-localización, donde las fronteras espaciales tradicionales parecen entrar en un proceso de indefinición (por ejemplo, en el caso de las fronteras nacionales y el Estado-nación), al tiempo que la textura misma de la experiencia parece ser afectada en su profundidad.

Así, el vaciamiento del espacio y el tiempo, como su permanente yuxtaposición, tienden a borrar las fronteras tradicionales, haciendo de la inmediatez y la universalidad aspectos centrales de la vida contemporánea. En esto reside precisamente la inquietante radicalidad con la que $M$. Heidegger se refiere a esta dialéctica entre lo local y lo mundial: "En una época en que el rincón más remoto del globo puede ser conquistado por la tecnología y abierto a la explotación económica; cuando cualquier suceso, por encima de dónde y cuándo ocurra, puede ser comunicado al resto del mundo a la velocidad deseada; cuando el asesinato del rey de Francia y una sinfonía en Tokio pueden 'experimentarse' en forma simultanea; cuando el tiempo no es otra cosa que velocidad, instantaneidad y simultaneidad, y el tiempo, en tanto historia ha desaparecido de la vida de todos los pueblos (...) entonces, sí, entonces, en medio de todo ese torbellino sigue en pie una interrogante que nos persigue como un espectro: ¿Para qué? ¿Adónde? ¿Entonces qué?" (Citado en Harvey, 2002; p. 233).

Siguiendo al pensador alemán (1997), la ausencia de cercanía en toda supresión de lejanía ha conducido al dominio de lo in-distante, y con ello a una transformación fundamental, tanto en el mundo de los objetos, como en la disposición del sujeto. Si es cierto que, tal como se ha indicado, la transformación en la experiencia del tiempo y el espacio han modificado profundamente la experiencia subjetiva de los individuos a escala planetaria, asentándola en la lógica de lo efímero, lo fragmentario y lo contingente, es posible reconocer una serie de consecuencias asociadas que afectan directamente las prácticas culturales e identitarias en que éstos se ven implicados. La transformación estructural en la organización espacio-temporal habrá de afectar a las sociedades contemporáneas en su conjunto; toda ella se verán desafiada por esta crisis en las formas de la experiencia.

\section{Auto-identidad, individuación y estilos de vida}

De este modo, en el transcurso de los últimos años, asistimos a un profundo y veloz proceso de re-estructuración de la vida social que afecta directamente tanto la experiencia individual como colectiva de sus miembros; proceso que se encuentra marcado por un incremento en la diversidad cultural y la opcionalidad de estilos de vida, como también por un profundo adelgazamiento de las instancias vinculantes y los relatos universales. Esto ha llevado a diversos pensadores a caracterizar la condición actual (llámese posmodernidad, modernidad tardía o segunda modernidad) como el advenimiento de lo transitorio, lo fluido, lo fragmentario y lo efímero, donde la referencialidad al tiempo y el espacio ha extraviado su significación tradicional. Los tiempos de los grandes relatos y la estabilidad de la razón desplegada no pueden sino hacer la experiencia de la comunidad perdida, cuyo sentido de trascendencia (épica) 
ha sido olvidado bajo las superficies destellantes de la transitoriedad y la fragmentación posmoderna.

Los ritmos espacio-temporales contenidos en la experiencia posmoderna han propiciado abundantes oportunidades para la socialización de los individuos en roles diversos y distintivos. Tal como lo señalara Bauman (2008), la diversificación de campos de acción contenidos en la Modernidad Líquida han de caracterizarse por una desorganización constante de los ritmos temporales y espaciales que estimulan prácticas culturales y socio-políticas marcadas por una creciente fragmentación, discontinuidad y yuxtaposición de lógicas contingentes de sentido. En este contexto, es posible sostener, siguiendo a Touraine (1997), que tras las luchas por los derechos cívicos, políticos, sociales que caracterizaron la sociedad desde el siglo XVII hasta el silgo XX, asistimos en la actualidad a un complejo escenario en el cual el tema central es el de los derechos culturales y el derecho a la individuación.

La deconstrucción de las lógicas de significación social solidamente edificadas que caracterizaron la modernidad en su solidez (Bauman, 2007) ha afectado directamente la experiencia individual, colectiva e institucional; aún cuando sus tiempos no sean necesariamente los mismos. La dificultad histórica que ha experimentado la estructura social (institucionalidad) al momento de proveer a los individuos de campos o módulos de sentido aglutinadores (proyectos de vida) y la tendencia de estos a canalizar individual y reflexivamente sus intereses y preocupaciones (estilos de vida), sumado al profundo proceso de redefinición entre lo local y lo global (como consecuencia de la globalización), han configurado una compleja situación en la cual la subjetividad pareciera desbordar los contenedores institucionales; abriendo un inédito campo histórico definido por la heterogeneidad de significados posible (hipertextualidad en la que los márgenes de tolerancia y acción se han expandido de manera exponencial), pero también por contextos cambiantes de inseguridad e incertidumbre donde los individuos deben construir cotidiana y privadamente su identidad personal. Contexto creciente de fragmentación que afecta tanto los referentes simbólicos (padre, profesores, guías espirituales, deportistas, etc.), como también los ámbitos en donde los procesos de significación se llevan a cabo (familia, escuela, iglesia, actividades deportivas, etc.).

Tal como lo señalara U. Beck (1996), "hoy los hombres no son liberados de las permanentes certezas religioso-trascendentales en el seno del mundo de la sociedad industrial -tal como ocurriera en la primera modernidad-, sino fuera, en la turbulencia de la sociedad mundial del riesgo" (p. 205); sociedad que emerge precisamente en el momento en el cual los peligros decididos y producidos socialmente sobrepasan los límites de los sistemas de normas sociales en relación a la seguridad, y donde el riesgo no asecha silenciosamente desde un exterior (ir)reconocible, sino más bien desde una interioridad sistémica inscrita en la lógica implícita de la toma de decisiones: no hay seguridad sin riesgo. Las sociedades modernas avanzadas operarían mediante la coexistencia problemática de dos modulaciones de la modernidad, oscilando permanentemente entre la expansión de la opcionalidad y la autonomía, por un lado, y la creciente expansión de riesgos, por otro; "así como en el siglo XIX la modernización ha creado la imagen de la sociedad industrial disolviendo a la sociedad estamental agraria, la modernización disuelve los contornos de de la sociedad industrial, y la continuidad de la modernidad origina otra configuración social" (Beriain, 1996; p. 13).

El individuo, de esta forma asediado, debe asumir la tarea de construir su autobiografía, es decir, reorganizar su experiencia de y en la realidad, al interior de un proceso de permanente mutación, donde el anhelo de comunidad de sentido (universo 
simbólico) adviene en la forma de un vaciamiento de los contenedores y las representaciones sociales preexistentes, lo que supone una búsqueda por actualizar las redes de protección en espacios diversos metafóricamente figurados en laboratorios de significación y experimentación. En esta dinámica del flujo constante, la reflexividad y autonomía individual buscan, en lo que pareciera ser un duelo mal realizado, exasperadamente asirse a experiencias simbólicas que encuentran su correlato en los misceláneos fragmentos de institucionalidad que procedieron de la transformación de la vida social de la primera modernidad, o simplemente se ven obligados a producir o crear ellos mismo espacios de simbolización (gestualidades, emocionalidades compartidas, etc.), que en muchos casos reclama fragmentos dispersos de distintos ámbitos, tanto locales como foráneos (mixturación e hibridez cultural). La sociedad tal como lo señalara U. Beck (2002)- no es ya el hogar de una humanidad preconstituida, sino más bien un amalgama de distintas y divergentes culturas socialmente auto-trabajadas.

Un claro ejemplo de esta mutación se encuentra representado por la familia y la vida amorosa. Siendo tradicionalmente asociada a una unidad de referencia básica en el análisis sociológico, que operaba como indicador clave en los estudios de estratificación social, el microcosmos de la unidad familiar ha experimentado un profundo proceso de resquebrajamiento, donde el todo analítico que tiempo atrás constituyó, comienza a disipar su significación social, espacial y económica; al tiempo en que el fenómeno de la convivencia/pareja ha ingresado en un campo de disolubilidad conceptual: "¿qué es una pareja cuando la pareja ya no se define según un certificado de matrimonio ni según la sexualidad?" (Beck, 2002; p. 15). Ambas modalidades de contención social, entendiéndolas como instancias de significación, han sufrido un profundo proceso de resignificación.

De este modo, los sentimientos de pertenencia a una comunidad ideal de sentido íntimamente articulado, ha sido desplazada por lógicas de sentido y deseo parceladas, cada una de las cuales tiende a materializarse, a falta de una matriz universal, en comunidades interpretativas o estéticas recíprocamente escindidas; cada una de las cuales representa un punto en la amplia y discontinua red de anhelos y demandas identitarias (comunidades imaginadas). Impresas con la marca distintiva de la desvinculación y la reflexividad (e incluso por la virtualidad y la impersonalidad muchas veces), estas instancias reflejas de autoconstrucción de la identidad asumen más la forma de comunidades emocionales, basadas en relaciones lúdicas y vínculos reciclables, que en relatos unificadores provistos de lógicas de sentido compartido; aún cuando ciertamente la experiencia emocional y estética de los diversos sistemas culturales reclama ciertos grados de construcción de sentido socialmente compartido (redes de contención donde el sujeto es actualizado permanentemente).

El proceso de individuación, acompañado de la reflexividad y autonomía que le son intrínsecos, ha de posibilitar el hecho de que la experiencia privada de tener una identidad personal que descubrir adquiera una dimensión propiamente política, en donde los derechos culturales e individuales han de ocupar un lugar privilegiado. Ética del descubrimiento del yo que ha de encontrar en los derechos reproductivos, la sexualidad, la corporalidad, la planificación familiar, los derechos civiles, la afectividad, el destino personal, la constitución pública del individuo, ámbitos de acción que tienden a reducir la asimetría entre racionalidad instrumental y racionalidad simbólica que habría caracterizado la modernidad en su primera fase. Desde la globalización, la crisis de las tradiciones culturales y las formas tradicionales de estructuración social hasta las relaciones entre los sexos, la intimidad y las disposiciones corporales, todo pareciera transitar de la mano de una reflexión constante de los individuos. 
En esta vorágine de tramas de significación identitaria, que trae consigo el proceso de fragmentación espacio-temporal, los individuos tienden a definirse mediante sus propias elecciones, preferencias y obligaciones en un mundo que no puede ya ser vivido en términos de totalidad; cuya producción social (interacción) asume la forma transpuesta de una permanente negociación de contenidos simbólicos que tiene lugar en un contexto marcado por la experiencia de lo contingente: "el proyecto reflexivo de sí mismo, que consiste en al mantenimiento de la coherencia en las narraciones biográficas, a pesar de su continua revisión, tiene lugar en el contexto de las múltiples posibilidades filtradas a través de los sistemas abstractos (...) el plan de vida organizado reflexivamente (...) se convierte en un rasgo central de la estructuración de la auto-identidad" (Giddens, 1996; p. 38).

De este modo, la semántica de la contingencia se enlaza con una temporalidad y especialidad en permanente apertura, inscribiéndose en la estructura interna de la recursividad reflexiva (pos)moderna. Todo puede y debe ser negociado, pues las normas de las que se derivan las respuestas y comportamientos se encuentran poco claras, o, en última instancia, no se encuentran socialmente compartidas. La metáfora del collage parece condensar la alta complejidad que la vida cultural contemporánea acusa, donde la yuxtaposición, la paradoja y la discontinuidad desplazan las modalidades armónicas de la identidad personal y colectiva tradicionales (identidades unidimensionales y univivenciales); fenómeno que ciertamente posee un gran impacto en los supuestos profundos de la organización social, demandando de estos índices de plasticidad que no siempre pueden ser satisfechos. La experiencia de la producción de comunidades de sentido e identidad ha de inscribirse en la lógica móvil de lo nómade (cultura del evento), abandonando sus tradicionales contenedores y modalidades sedentarias.

La lógica de las distribuciones espaciales, y no sólo las experiencias personales, ha de atender a este alto grado de plasticidad, convirtiendo la forma misma en la que las ciudades, los barrios, los parques, etc., son concebidos, demandando la atención de urbanistas y arquitectos. Emergen comunidades urbanas enmarañadas e independientes que se insertan en complejos de barrios urbanos, que a su vez configuran ciudades dentro de ciudades. Indiferenciación de las fronteras espaciotemporales que se orienta a la producción masiva de productos relativamente personalizados que expresan una gran cantidad y diversidad de estilos; el gusto está lejos de constituir una categoría estática (Collage urbano). Ciertamente este ámbito ha constituido un campo central para la cosmovisión posmoderna, que ha de recusar los presupuestos estéticos de la especialidad modernidad: "Si se tienen en cuenta las necesidades de la 'heterogeneidad de comunidades urbanas y culturales del gusto', la arquitectura debe alejarse del ideal de un meta-lenguaje unificado, disolviéndolo en discursos altamente diferenciados (...) El lenguaje de la arquitectura se disuelve en juegos de lenguaje altamente especializados, cada uno de los cuales conviene a una comunidad interpretativa diferente (...) el resultado es la fragmentación, a menudo adoptada de manera consciente (...) El eclecticismo es la evolución natural de una cultura de opciones" (Harvey, 2002; p. 102-107).

Lo que sucede en este contexto estructural de solubilidad no debe, sin embargo, ser concebido simplemente como una mutación acelerada de las conductas individuales y/o colectivas, cuya colonización institucional se presenta actualmente insuficiente, sino también como la fragmentación creciente de la experiencia misma del individuo que habrá de pertenecer simultáneamente a distintos circuitos de significación social (comunidades interpretativas y travestismo cultural), muchas veces autónomos y 
dispares entre sí: toca a los individuos y grupos controlar, dentro de estos dominios, lo que ha ser considerado inter-subjetivamente como conocimiento válido (Harvey, 2002; Giddens, 1997, Beck, 2006). Experiencia de la atomización de lo social en redes flexibles de juegos de lenguaje que supone que cada individuo puede recurrir a un conjunto diferentes de códigos según la situación en que éste se encuentre (deseos y anhelos), sean estos acordes o no entre sí. Se acusa una dispersión de la experiencia subjetiva que, estimulada por las transformaciones de la conciencia del tiempo y el espacio, amenaza con suvertir su tan preciada intimidad (con las consecuencias sociopolíticas que estos significa); el sujeto mismo parece disolverse en esta diseminación de juego de leguaje: la biografía personal adviene en la forma híbrida de una polisemia narrativa en permanente construcción, donde el yo ha perdido su unidad tradicional, inscribiéndose en las gramáticas de la multiplicidad, la yuxtaposición, la disyunción, la fluidez (Touraine, 1997).

En este sentido, la extraordinaria capacidad técnica de producción, consumo y circulación de bienes simbólicos, sumado a la reconfiguración de la dialéctica entre lo local y lo universal, modificaran radicalmente las condiciones materiales de existencia de los individuos a escala mundial, afectando no sólo los contenidos de la vida social, sino también su naturaleza. La pérdida de fe en el carácter inevitable del progreso, sumado al creciente malestar frente a las categorías fijas dispuestas por la modernidad, han de poner en suspenso la creencia racionalista según la cual existiría una única forma de representación correcta, cuya elucidación proporcionaría los medios óptimos para alcanzar los fines de la Ilustración (Harvey, 2002).

\section{Políticas del fragmento y Sociedad del Riesgo}

Ahora bien, esta heterogeneidad y fragmentación cultural expresada en la dispersión de nubes de elementos narrativos y comunidades interpretativas es sólo el revés positivo de este tránsito estetizante, cuya atracción guarda una íntima relación con el condicionante emancipatorio-liberador que la posmodernidad propone en relación a la alteridad, en contraposición con la modernidad: "La idea de que todos los grupos tienen derecho a hablar por si mismos, con su propia voz, y que esa voz sea aceptada como auténtica y legítima, es esencial a la posición pluralista del posmodernismo" (Harvey, 2002; p. 65). Sin embargo, si no es posible aspirar a una representación relativamente unificada del mundo, ni a una concepción que tome en cuenta su carácter de totalidad llena de conexiones y diferenciaciones, conduciéndolo al perpetuo desplazamiento de fragmentos volatizados, ¿cómo es posible aspirar a actuar en forma coherente y conjunta con relación a los desafíos que el nuevo escenario internacional presenta? "La respuesta posmodernista -insiste Harvey- consistiría simplemente en afirmar que, si la representación y la acción coherentes son represivas o ilusorias (y por lo tanto están condenadas a disiparse y anularse a sí mismas), ni siquiera deberíamos intentar comprometernos con un proyecto global" ( $p$. 69). Esta es precisamente la deriva perversa que la reconfiguración posmoderna del lazo social pareciera evidenciar.

Por un lado, nos hemos liberado de las cadenas de la dependencia subjetiva y, por lo tanto, contamos con un grado de libertad individual mucho más amplio. Pero esto se logró a expensas de dar a los otros un trato objetivo e instrumental. No nos quedaba otra alternativa que relacionarnos con otros son rostro a través del frío y despiadado cálculo de los intercambios monetarios capaces de coordinar la creciente división social del trabajo (...) Nuestra única salida, parece decir, es cultivar un individualismo impostado recurriendo a los signos de status, a la moda o a las marcas de excentricidad individual (Harvey, 2002; p. 42). 
Es posible señalar, siguiendo a M. Berman (1989), que la experiencia tardía de lo moderno dispone mecanismo y dispositivos que involucran a la humanidad en su totalidad, pero sólo en la forma de una modulación paradójica de su unidad; cuya especificidad arroja el ser genérico en una vorágine de perpetua desintegración e innovación: unión y desunión, lucha y contradicción, ambigüedad y angustia. Esta complejidad de lo social evidenciada en la experiencia posmoderna de la desvinculación ha sido conceptualizada por A. Touraine (1998) en términos de una creciente desaparición de los patrones reguladores que gobernaron la experiencia de la modernidad industrial-capitalista, como también de sus expresiones sistémicoinstitucionales ('Des-modernización'): "sólo la desaparición de lo que se llama sociedad u orden social permite la combinación conflictiva pero necesaria entre una vida social, cada vez más reducida a procesos de cambio, y un principio de igualdad que ya no se funda sobre la fraternidad entre las criaturas de Dios, sobre la razón, sobre la realización del espíritu en la historia o sobre el interés general del cuerpo social, sino sobre el único derecho de cada individuo de conjugar libremente su participación en el universo instrumental con el mantenimiento, la reintegración y la continua reconstrucción de su identidad personal y colectiva" (p. 81).

Sin pretender instalar una concepción apocalíptica tendiente a afirmar la disolución del lazo social, como tampoco el paso de las colectividades sociales al estado informe de una masa compuesta de átomos individuales, debe señalarse que el problema evidenciado no es en ningún caso menor. Una visión de este tipo terminaría -tal como lo señala lucidamente Lyotard (1991)- por inscribir la gravedad en cuestión en la antigua creencia metafísica de una comunidad de sentido orgánica y descontaminada, extraviada en la experiencia accidental de la razón; consideración que reconduciría el problema a un ámbito estéril. Ahora bien, la dificultad de pensar la construcción de una política orientada al bienestar común, en un campo de acción marcado por la inmediatez y la fragmentación del espacio, se encuentra íntimamente ligado a la cuestión de la comprensión espacio-temporal dispuesta por las coordenadas de un mundo en el cual las luchas por los derechos cívicos, políticos y sociales -que caracterizaron la sociedad desde el siglo XVII hasta el siglo XX- han sido desplazadas por el tópico de los derechos culturales. La experiencia privada de tener una identidad personal que descubrir (proyecto de realización reflejo del yo) ocuparía el lugar que tradicionalmente reclamaban los esfuerzos por liberar a los individuos y los grupos de las ataduras del pasado y el dominio ilegítimo de algunos individuos sobre otros, pero esta vez en un contexto marcado por altos índices de riesgo y peligrosidad sistémicos. ${ }^{4}$

"Quien concibe la modernidad como un proceso autónomo de innovación debe tener en cuenta su deterioro cuyo reverso es el surgimiento de la sociedad del riesgo", con esta advertencia U. Beck (1996; p. 201) nos invita a re-pensar la nueva configuración de la vida social en condiciones de modernidad tardía. Según este argumento, la sociedad del riesgo designaría una fase de desarrollo de la sociedad moderna en la que a través de las dinámicas de cambio la producción de riesgos escapa, de manera progresiva, de las instituciones de control y protección de la institucionalidad de la temprana modernidad. Junto al desarrollo de una pluralidad de opciones, o precisamente con ocasión de ello, la modernidad tardía se caracterizaría por la emergencia sistémica de riesgos, cada uno de los cuales se alojaría en la lógica misma de la toma de decisiones. Toda decisión se opera en un régimen de riesgo que es intrínseco a dicha acción, y donde las coordenadas de la primera modernidad se evidencian insuficientes. La pregunta referiría precisamente al modo en que, en las condiciones actuales de debilitamiento del vínculo social, la modernidad podría hacer frente a los riesgos 
implícitos en todo orden de modernización, los cuales no sólo amenazarían con peligros residuales, sino con la posibilidad misma de un régimen social (globalización de los riesgos).

Otro ámbito que complejiza el ya comentado, corresponde a la dificultad de establecer lógicas de articulación entre pasado y futuro en un contexto marcado por la inmediatez y la sobrevaloración de un presente que pareciera eternizarse. Esta particular forma de experimentar, interpretar y estar en el mundo, ha sido, metafóricamente hablando, asimilada con el fenómeno de la esquizofrenia. A diferencia de la primera modernidad (Beck, 2002) o la modernidad sólida (Bauman, 2007), caracterizada por la alienación, los presupuesto psicológicos ligados con la personalidad, la motivación y el comportamiento, en la condición posmoderna han de referir a un desorden lingüísticodiscursivo relacionado con la ruptura de la cadena significante que conlleva a un universo fragmentado de significantes diferentes y desvinculados; donde la identidad se actualiza permanentemente en un proceso de creación biográfica que asume la forma de una fragmentación temporal del sujeto. Tal como lo señalara D. Harvey (1989), siguiendo los trabajos de F. Jameson, "ya no podemos concebir al individuo como alienado en el sentido clásico marxista, porque estar alienado supone un sentido del propio ser coherente y no fragmentado, del que se está alienado (...) es sólo en función de este sentido centrado de identidad personal como los individuos pueden realizar proyectos en el tiempo, o pensar en forma convincente la producción de un futuro que sea significativamente mejor que el tiempo presente y el tiempo pasado" (p. 71).

De esto se deriva, una suerte de crisis de la utopía, que podría caracterizarse como la imposibilidad de proyectar estrategias para pensar y producir un futuro alternativo al permanente devenir de presentes fijos, como también una recreación fetichizada del pasado, donde éste se ve gradualmente cercado en la forma de una vasta colección de imágenes devenidas espectáculo: la lógica (pos)moderna del simulacro parece ejercer un efecto disolutivo en lo que solía ser el tiempo histórico, la sociedad se ve privada de su intrínseca historicidad (Jameson, 2007; Debord, 1995).

Finalmente, esta sobrevaloración de la inmediatez y la fragmentación del lazo social, sumado a los procesos de globalización que se encuentran a su base, ponen de manifiesto un riesgo radical, el cual consistiría en la universalización de conflictos tradicionalmente regulados, como también el surgimiento de nuevos conflictos de bajo pero intenso alcance. La posibilidad de que emerjan conflictos internacionales de alto alcance, que afecten a los individuos independientemente de donde vivan y de los privilegios que estos posean, se ha convertido en una preocupación permanente (Huntington, 2001); donde la posibilidad de una muerte común ha constituido un tópico central en el debate internacional. El resurgimiento de comunitarismos religiosos y étnicos, el fuerte componente emocional que han evidencia las comunidades de sentido y la introducción de conflictos basados en la distribución de los daños socialmente producidos (conflicto de atribución que coexiste con los conflictos de distribución de los bienes sociales), son solo algunos de los fenómenos que amenazan con circunscribir nuevos ámbitos de conflictividad social, para los cuales la contemporaneidad no parece encontrarse preparada (Touraine, 1998).

\section{Conclusiones}

En el transcurso del presente trabajo, hemos reconstruido un movimiento de pensamiento que ha hecho de la comprensión espacio-temporal posmoderna su objeto de estudio por excelencia. Hemos caracterizado la traducción que de dicha compresión 
ha elaborado la primera modernidad, para posteriormente esbozar las transformaciones que ésta ha experimentado en lo que se ha denominado tránsito a la posmodernidad; asimismo, hemos comentado las implicancias que dicha mutación ha evidenciado en las prácticas y procesos de significación en la vida cotidiana de los individuos, para finalmente, delinear los desafíos que las nuevas formas de organización, simbólica y material, han comenzado ha revelar respecto de la naturaleza del lazo social. Hemos expuesto, además, que estas mutaciones presentan una difícil conceptualización, puesto que su desenvolvimiento se expresa contemporáneamente más como tendencias o corrientes que como condiciones estructurales y sistémicamente establecidas. En lo que sigue, se intentarán sistematizar las conclusiones más significativas que pueden extraerse de estas tendencias, a la luz del presente informe.

1) La condición posmoderna acontece en la forma de una radicalización de las coordinas de la modernidad, que termina por desbordar su horizonte cognoscitivo. Es posible sostener que, con los procesos de globalización económico-políticos y la impermeabilización de la cultura posmoderna, la comprensión espacio-temporal dispuesta por la modernidad ha experimentado una profunda transformación, la cual, sin embargo, guarda íntima relación con ésta. En este sentido, no cabe duda de que la nueva condición histórica que estas transformaciones acusan encuentra su condición de posibilidad en la concepción moderna del tiempo y el espacio; mas sólo como una radicalización de los supuestos en ésta contenidos: la experiencia posmoderna, antes que una ruptura radical con la modernidad, pareciera evidenciar una profunda dependencia, la cual, en su desarrollo, asume la forma de una consumación o desbordamiento de las coordenadas modernas, que hacen de la posmodernidad una condición intraducible en términos modernos (colapso de la especificidad y las identidades espaciales, aceleración descontrolada de los procesos temporales, etc.). Todo ocurre como si la comprensión espacio-temporal moderna pusiera en juego dispositivos que en su radicalización abandonaran la matriz inicial en la cual fueron estructurados, abriendo la posibilidad de una nueva condición histórica que escapa, y ciertamente trasciende, los criterios de inteligibilidad propiamente modernos (el caso más significativo al respecto, mas no el único, se encuentra representado por el desbordamiento del contenedor territorial que durante el auge de la modernidad constituyo el Estado-nación, el cual no sólo ha repercutido en el debilitamiento de un proyecto colectivo de alto alcance, sino también en la creciente desaparición de los antiguos lenguajes nacionales).

2) Los procesos y dispositivos dispuestos por la condición posmoderna propician el desarrollo de una individuación, una autonomía y una reflexividad de alta intensidad. El contexto de fragmentación y desvinculación del mundo social tradicional, que supone, no sólo un modo de interpretar el mundo, sino también de habitarlo, no debe conducirnos a un razonamiento unidimensional, según el cual el individuo es determinado estructuralmente por las condiciones materiales e históricas de su existencia (sistemas abstractos); aun cuando ciertamente estos afectan su intimidad subjetiva. Esto supondría negar la experiencia de una reflexividad activa intensificada, fenómeno que condiciona, según los diversos estudiosos, el desenvolvimiento autónomo de la subjetividad en los atolladeros de la modernidad tardía. Las transformaciones experimentadas en las estructuras objetivas de la vida social han condicionado, en este sentido, el surgimiento de desafíos cualitativamente distintos de aquellos que gobernaron la experiencia subjetiva de la primera modernidad, reclamando la configuración de mapas simbólico-materiales de alta complejidad. Como nunca antes en la historia, el sujeto se ve expuesto a procesos intensos y abstractos 
de individuación, autonomización y reflexivididad, sin los cuales su experiencia del mundo no sería posible.

Las políticas de la vida constituyen un eje clave en este nivel argumentativo. No estando orientas a las condiciones de liberar a los individuos para que estos realicen sus propias opciones, puesto que se constituyen desde su inicio en política de opción (estilos de vida), las políticas de la vida refieren a cuestiones políticas que derivan de procesos de realización del yo en circunstancias pos-tradicionales, donde las influencias universalizadoras se introducen profundamente en el proyecto reflejo del yo, al tiempo en que estos procesos de realización del yo influyen en estrategias globales (Giddens, 1997). Inserta en este entramado, la tensión entre individuo e institución (entendida ésta en sentido amplio), involucra una plasticidad tanto de las instituciones como de la personalidad; donde la diversificación de prácticas socio-culturales crea, al tiempo que es condicionada por, lenguajes y prácticas institucionales de significación parcial que han sido concebidas en términos de comunidades de sentido (quizás los ejemplos más representativos sean los movimientos estudiantiles y feministas).

En este sentido, las transformaciones estructurales que la reorganización de la experiencia espacio-temporal supone no deben sólo ser interpretadas en términos institucionales, reclamando el reconocimiento de las alteraciones que imprimen en la vida cotidiana. Sus implicancias no sólo se expresarían en transformaciones extensas, sino también en transformaciones que afectan las dimensiones más íntimas de la experiencia subjetiva; transformación de la intimidad (Giddens, 1992) que supone mecanismos precisos de auto-identidad que, afectando los contenidos y la naturaleza del vínculo social, son modelados por las instituciones de la modernidad tardía, a las cuales, sin embargo, aquellos también modelan.

3) Las políticas de la vida han desplazado las políticas de emancipación, lo que expresa desafíos fundamentales cuya resolución pareciera no ser aún elucidada. La fragmentación creciente del circuito social que las políticas de la vida presupone, en oposición a las tradicionales políticas de la emancipación -orientadas sobretodo en liberar a los individuos y los grupos de las trabas que afectan adversamente sus posibilidades de vida común-, han propiciado un estado de cosas donde la pregunta por un proyecto aglutinador de bienestar común pareciera haber perdido su centralidad histórico-existencial. El subjetivismo radical pareciera rebasar la institucionalidad, poniendo en riesgo la posibilidad misma de un estar-en-común: se vuelve necesario tomar en cuenta exigencias simultaneas de diversos actores relativamente autónomos, como también considerar las formas impredecibles mediante las cuales estos orientan su acción a los fines perseguidos. Es más, la imposibilidad de apelar a una representación común del mundo, ni a una concepción que reconozca la conexión que toda diferenciación supone en términos dialécticos, sumado a la creciente filtración estructural del riesgo, han comenzado a verse agravados por la proliferación de conflictos inmunitarios que ponen en cuestión la posibilidad misma de la comunidad (Esposito, 2003; Nancy, 2000).

En el momento actual, el gran conflicto se encontraría determinado por una objetividad total impersonal y un subjetivismo radical que amenaza con subvertir la reflexividad institucional. Se reconoce en este sentido, un replanteo de la fenomenología del vínculo social, donde los dispositivos tradicionales de codificación y contención social (familia, escuela, iglesia, partido, Estado) parecen presentarse anacrónicos en una época marcada por la transitoriedad y la fugacidad; donde los índices de riesgo global aumentan de modo exponencial. 
En consecuencia, y tal como puede apreciarse, si bien es cierto que la modernidad líquida, como ha sido conceptualizado por Z. Bauman el periodo que se inicia tras la convulsión social de la primera mitad del siglo $\mathrm{XX}$, ofrece un entorno que, proponiendo aventura, alegría, autonomía y poder, evidencia también una sombría amenaza de destrucción, donde la posibilidad de una muerte común no constituye ya una ficción marginal en el debate internacional, atravesando las fronteras geográficas, étnicas, clasistas, nacionales y religiosas. RM

\section{Bibliografía}

Adorno, Th. \& Horkheimer, M. (1998). Dialéctica de la llustración. Fragmentos filosóficos. España: Trotta.

Bauman, Z. (2006). La globalización. Consecuencias humanas. Buenos Aires: Fondo de Cultura Económica.

Bauman, Z. (2007) Modernidad Líquida. Buenos Aires: Fondo de Cultura Económica.

Beck, U. (1996). Teoría de la sociedad del riesgo. En: Beriain, J. (comp.). Las consecuencias perversas de la Modernidad. Modernidad, contingencia y riesgo (pp. 201-222). Barcelona: Anthropos.

Beck, U. (2002). Libertad o capitalismo. Conversaciones con Johannes Willms. Barcelona: Paidós.

Beck, U. (2006) La sociedad del Riesgo. México: Fondo de Cultura Económica.

Beriain, J. (1996). El doble sentido de las consecuencias perversas de la modernidad. En: Beriain, J. (comp.). Las consecuencias perversas de la Modernidad. Modernidad, contingencia y riesgo (pp. 7-29). Barcelona: Anthropos.

Berman, M. (1989). Todo lo sólido se desvanece en el aire. La experiencia de la Modernidad. Buenos Aires: Siglo XXI.

Debord, G. (1995). La sociedad del espectáculo. Santiago de Chile: Naufragio.

Esposito, R. (2003). Communitas. Origen y destino de la comunidad. Buenos Aires: Amorrortu.

Giddens, A. (1992). La transformación de la intimidad. Sexualidad, amor y erotismo en las sociedades modernas. Madrid: Cátedra.

Giddens, A. (1996). Modernidad y autoidentidad. En: Beriain, J. (comp.). Las consecuencias perversas de la Modernidad. Modernidad, contingencia y riesgo (pp. 33-71). Barcelona: Anthropos.

Giddens, A. (1997) Modernidad e identidad del Yo. El yo y la sociedad en la época contemporánea. España: Península.

Harvey, D. (2004). La condición de la posmodernidad. Investigaciones sobre los orígenes del cambio cultural. Buenos Aires: Amorrortu.

Heidegger, M. (1997). Filosofía, ciencia y técnica. Santiago: Universitaria.

Huntington, S. (2001). El choque de las civilizaciones y la reconfiguración del orden mundial. Buenos Aires: Paidós. 
Jameson, F. (2007). El posmodernismo, o, la lógica cultural del capitalismo avanzado. Barcelona: Paidós.

Lyotard, J. F. (1991). La condición posmoderna. Informe sobre el saber. Buenos Aires. Cátedra.

Nancy, J-L. (2000). La comunidad inoperante. Santiago de Chile: ARCIS/LOM.

Touraine, A. (1997) ¿Podremos vivir juntos? Iguales y diferentes. Buenos Aires: Fondo de Cultura Económica.

Touraine, A. (1998) Igualdad y diversidad. Las nuevas tareas de la Democracia. Argentina: Fondo de Cultura Económica.

\section{Notas}

1 Al momento de señalar la confusión categorial que con este tránsito aqueja a la intelectualidad internacional, Harvey ha de poner en evidencia, mediante la instalación de incógnitas irresueltas que permitiría definir una interpretación precisa del cambio cultural, la incertidumbre que parece gobernar actualmente el debate modernidad-posmodernidad: "¿acaso el posmodernismo representa una ruptura radical con el modernismo, o se trata sólo de una rebelión dentro de éste último contra una determinada tendencia del alto modernismo como la que encarna, por ejemplo, la arquitectura de Mies van der Rohe y las superficies vacías de la pintura expresionista abstracta de los minimalistas? ¿Es el posmodernismo un estilo (...) o debemos considerarlo estrictamente como un concepto de periodización? (...) ¿Tiene un carácter revolucionario a causa de su oposición a todas las formas de meta-relato (incluyendo el marxismo, el freudismo y todas las formas de razón de la Ilustración) y su preocupación por otros mundos y por otras voces tan largamente silenciados (mujeres, gays, negros, pueblos colonizados con sus propias historias? ¿O se trata simplemente de la comercialización y domesticación del modernismo, y de una reducción de las aspiraciones ya gastadas de este último a una laissez-faire, a un eclecticismo mercantil de 'todo vale'? Por lo tanto, ¿socava la política neoconservadora o se integra a ella? ¿Y acaso atribuimos su aparición a una reestructuración radical del capitalismo, a la emergencia de una sociedad posindustrial, o lo consideramos como un arte de la inflacionaria o como lógica cultural del capitalismo tardío?" (Harvey, 2004; p. 59).

${ }^{2}$ Debido al consenso en torno a las transformaciones operadas en la comprensión espacio-temporal en el mundo moderno, como también la riqueza teórica de cada una de estas conceptualizaciones, en lo que sigue se intentará utilizar el concepto elaborado por cada uno de los autores según su tratamiento sea necesario. En este sentido, al momento de abordar los trabajos de Harvey, Giddens, Beck o Touraine intentare mantener en la argumentación el concepto preciso por cada uno de estos utilizado; esto básicamente guarda relación, tal como se ha señalado, con la riqueza escritural evidenciada por cada uno de los autores.

3 No deben confundirse, advierte Giddens, los mecanismo de desenclave con el proceso moderno de diferenciación, puesto que mientras este último refiere a la especialización de las funciones sociales modernas, el primero guarda íntima correspondencia con la aceleración del distanciamiento entre tiempo y espacio introducida por la lógica virtual y fluida de la dinámica global.

${ }^{4}$ La relación y diferenciación entre riesgo y peligro guarda íntima relación con la asimétrica oposición que se estructura entre la experiencia soberna de la decisión y las consecuencias asociadas que en ésta tienen lugar. Niklas Luhmann se ha referido a esta compleja relación/diferenciación en los siguientes términos: "Se habla de riesgos cuando los daños futuros obedecen a la decisión tomada por uno mismo. Quien no viaja en avión jamás puede estrellarse. Por peligros se entiende los daños que sobre uno recaen desde el exterior. Por ejemplo, los desperfectos de un avión accidentado caen sobre un sujeto produciéndole la muerte (...) Peligros conocidos (...) devienen riesgos en la medida en que se les puede suspender evitando determinadas decisiones. Pero con esto sólo se esclarece la mitad del hecho. Ya que con las decisiones se incrementan también los peligros y bajo la forma de peligros que parten de las decisiones ajenas. (...) Así el orden socia1 hoy atraviesa la diferencia entre riesgo y peligro. Lo que para uno es riesgo para el otro es peligro. El fumador puede arriesgarse ante un hipotético cáncer, sin embargo para el otro tal acción se constata como peligro. Asimismo, el conductor que efectúa un adelantamiento arriesgado, el que construye y el que dirige el funcionamiento de centrales nucleares, la investigación tecnológica de ingeniería genética -no se necesita más ejemplos" (citado en Beriain, 1996; p. 210).

Revista Mad. No 22, Mayo de 2010. Departamento de Antropología. Universidad de Chile http://www.revistamad.uchile.cl/22/Carrasco_05.pdf 